\title{
Universal Metric for Assessing the Magnitude of the Uncertainty in the Measurement of Fundamental Physical Constants
}

\author{
Boris Menin \\ Refrigeration Consultancy Ltd., Beer-Sheba, Israel \\ Email: meninbm@gmail.com
}

How to cite this paper: Menin, B. (2017) Universal Metric for Assessing the Magnitude of the Uncertainty in the Measurement of Fundamental Physical Constants. Journal of Applied Mathematics and Physics, 5, 365-385.

https://doi.org/10.4236/jamp.2017.52033

Received: December 21, 2016

Accepted: February 14, 2017

Published: February 17, 2017

Copyright $\odot 2017$ by author and Scientific Research Publishing Inc. This work is licensed under the Creative Commons Attribution International License (CC BY 4.0).

http://creativecommons.org/licenses/by/4.0/

\section{(c) (i) Open Access}

\begin{abstract}
In this paper, we aim to verify the numerical magnitude of the relative uncertainty in the measurement of fundamental physical constants. For this purpose, we use a metric called comparative uncertainty with which an a priori mismatch between the selected model and the observed physical object is checked. The comparative uncertainty is caused by the finite number of dimensional variables of the applied model. We show a comparison of the achieved values of the relative and comparative uncertainties of the gravitational constant, Planck's constant, Boltzmann's constant, and fine structure constant, according to data published in the scientific literature over the last 7 - 15 years. The results generally agree well with CODATA recommendations. We show that the comparative uncertainty as a universal metric can be used for the identification of recommended target values of the relative uncertainty in the field experiments.
\end{abstract}

\section{Keywords}

Fundamental Physical Constants, Information Theory, Mathematical Modeling, Similarity Theory, Uncertainty

\section{Introduction}

The physical laws express the quantitative relationship between different physical quantities in mathematical form. They are set on the basis of generalization of obtained experimental data, and reflect the objective laws existing in nature. So fundamentally important is it that all physical laws are an approximation to reality, since the construction of the theories is formulated by certain models 
of phenomena and processes. Outside these models, the laws do not work or work poorly. Therefore, they have certain limits of applicability. In other words, physical laws give good predictions in a specific area of experimental conditions, and the corresponding theory explains them. A more accurate or more correct theory has a wider range of applications. Scientists believe that physical laws, at least, enable us to predict results to an arbitrary accuracy. For example, classical mechanics, based on Newton's three laws and the law of universal gravitation, is valid only for the motion of bodies with velocities much smaller than the speed of light. If the velocities of the bodies are comparable to the speed of light, predictions of classical mechanics are wrong. Special relativity has successfully coped with these problems. In fact, all physical theories are limited. The correspondence principle requires that a new theory with the broader area of applicability be limited to the old theory within the limits of its applicability. Turning to the theory of new concepts creates important preconditions for further development.

Among the various explanations for the admissibility of the possible limits of applicability of physical laws, the following reasons are the most used. The first is the assumption that there is the limited detalization of phenomena, for which the Heisenberg inequality gives a quantitative expression. Secondly, the restrictions are determined by the real nature of the macroscopic instrument or measuring system. Most devices are presented, finally, as a solid. In principle, it could be argued that any device has an educational effect only within the field of reality where it is. Thus, research results should be expressed in terms of the macroscopic. In other words, concepts and images can be identified and are associated only with ordinary macroscopic views. The last argument is the point of view of the principle of the electromagnetic nature of all modern means of measurement and their role in determining the boundaries of experimental and measurement capabilities, and harmonization of the data with the theoretical postulate. Thus, there are possible explanations, but any quantitative approaches to estimate the difference between a model (i.e. a formulated physical law) and existing reality numerically, have not been proposed to date.

Regarding the fundamental physical constants, it should be noted that their values are the accuracy of our knowledge of the fundamental properties of matter. On the one hand, very often the verification of physical theories is determined by the accuracy of the measured physical constant. On the other hand, firmly established experimental data are put into the foundation of new physical theories.

In the study of physical constants, it is noteworthy that they are measured with very high accuracy, which is steadily increasing, which in itself is a testament to the development and perfection of techniques of physical experiment. Precision research on the measurement and specification of the values of physical constants and meticulous work on harmonization of data obtained by different methods and different groups of researchers are currently carried out. However, there is an urgent need to improve the accuracy of measurement of 
fundamental physical constants further. This is explained by the desire to improve the axiomatic basis of the International System of units (SI).

To assess the accuracy achieved in the measurements of fundamental physical constants, the concept of relative uncertainty is used. It should be mentioned that this method for identifying the measurement accuracy does not indicate the direction in which one can find the true value of a particular fundamental physical constant. In addition, it involves an element of subjective judgment [1]. For this reason, we offer another method of assessing the credibility of the obtained measurements results.

In [2], the specific novel foundations in modeling physical phenomena were established. For this purpose, the author discussed a representation of information theory for the optimal design of the model. A metric called comparative uncertainty, by which a priori discrepancy was between the chosen model and the observed material object, was verified. Moreover, the information quantity inherent in the model could be calculated, and proscribes the required number of variables that should be taken into account. It was thus concluded that in most physically relevant cases (micro- and macro-physics), the comparative uncertainty can be realized by field tests or computer simulations within the prearranged variation of the main recorded variable. This article is our attempt to speculate on how the fundamentally new concept of comparative uncertainty can be applied to assess for the identification of recommended target values of the estimated and required experimental relative uncertainty in the field measurements of fundamental physical constants.

\section{Required Techniques}

In a background paper [2], an approach, called the $\aleph_{\mathrm{SI}}$-hypothesis, for calculating the lowest uncertainty of the researched variable based on principles of information and similarity theories, is formulated. Following it, a certain uncertainty exists before starting an experiment due only to the known recorded number of variables. In turn, the dimensionless (DS) comparative uncertainty $\varepsilon$ of the DS variable $u$, which varies in a predetermined DS interval $\mathcal{S}$, for a given number of selected physical dimensional (DL) variables $z^{\prime \prime}$, and $\beta^{\prime \prime}$ (the number of the recorded primary physical variables), can be determined from the relation

$$
\varepsilon=\Delta u / S \leq\left[\left(z^{\prime}-\beta^{\prime}\right) /(\Psi-\xi)+\left(z^{\prime \prime}-\beta^{\prime \prime}\right) /\left(z^{\prime}-\beta^{\prime}\right)\right],
$$

where $\Delta u$ is the DS uncertainty of the physical-mathematical model describing the experiment of measurement of DS variable $u$ with the apriority chosen number of variables; $\xi$ is the number of primary physical variables with independent dimensions; SI includes the following seven $(\xi=7)$ basic primary variables: $L$-length, $M$-weight, $T$-time, $I$-electric current, $\Theta$-thermodynamic temperature, $J$-luminous intensity, $F$-amount of substance. The dimension of any secondary variable $q$ can only express a unique combination of dimensions of main primary variables in different degrees [3]: 


$$
q \supset L^{l} \cdot M^{m} \cdot T^{t} \cdot I^{i} \cdot \Theta^{\Theta} \cdot J^{j} \cdot F^{f}
$$

$l, m \cdots f$ are exponents of variables, the range of which has maximum and minimum value; according to [4], integers are as follows:

$$
\begin{gathered}
-3 \leq l \leq+3,-1 \leq m \leq+1,-4 \leq t \leq+4,-2 \leq i \leq+2, \\
-4 \leq \Theta \leq+4, \quad-1 \leq j \leq+1, \quad-1 \leq f \leq+1 ;
\end{gathered}
$$

the exponents of variables take only integer values [4], so the number of choices of dimensions for each variable $e_{k}, k=\{l, m \cdots f\}$ according to (3) is as follows:

$$
e_{l}=7 ; e_{m}=3 ; e_{t}=9 ; e_{i}=5 ; e_{\theta}=9 ; e_{j}=3 ; e_{f}=3
$$

the total number of dimensional options of physical variables equals $K^{*}=\prod_{l}^{f} e_{i}-1$

$$
K^{*}=e_{l} \cdot e_{m} \cdot e_{t} \cdot e_{i} \cdot e_{\theta} \cdot e_{j} \cdot e_{f}-1=7 \cdot 3 \cdot 9 \cdot 5 \cdot 9 \cdot 3 \cdot 3-1=76,544,
$$

where " -1 " corresponds to the occasion when all exponents of variables of primary variables in Equation (2) are treated to zero dimension; $\boldsymbol{\Pi}$ is a product of $e_{k}$; the value $K^{*}$ includes both required, and inverse variables (for example, $L$-length, $L^{-1}$-running length). This is why the object can be judged knowing only one of its symmetrical parts, while others structurally duplicating this part may be regarded as information empty [5]. Therefore, the number of options of dimensions may be reduced by $\omega=2$ times. This means that the total number of dimensional physical variables without inverse variables for SI equals

$$
\Psi=K^{*} / 2=38,272 ;
$$

$z^{\prime}$ is the total number of DL physical variables in the chosen class of phenomena (COP); in SI frames, every researcher selects a particular COP to study a material object. COP is a set of physical phenomena and processes described by a finite number of primary and secondary variables that characterize certain features of material object from the position with qualitative and quantitative aspects [6]. In studying mechanics, for example, which is widely applied for the Newtonian gravitational constant measurements with a torsion balance, the base units of SI are typically used: $L, M, T(L M T)$. In publications that study the Boltzmann constant, $\mathrm{COP}_{\mathrm{SI}} \equiv L M T \theta$ is usually realized; $\beta^{\prime}$ is the number of primary physical variables in the chosen COP.

Equation (1) quantifies $\Delta u / S$ caused by the limited number of variables taken into account in the theoretical or experimental analysis of fundamental physical constant value. It also sets a limit on the expedient increasing of the measurement accuracy in conducting experimental studies. In turn, $\Delta u / S$ is not a purely mathematical abstraction. It has a physical meaning, consisting of the fact that in nature there is a fundamental limit to the accuracy of displaying any observed material object, which cannot be surpassed by any improvement of instruments and methods of measurement. The reality of the environment is the obvious a priori condition for modeling the investigated material object. By allocating the interested process or phenomenon, the unknown relationships between the content of object and the environment are "broken". In this context, it 
is obvious that the overall uncertainty of the model including inaccurate input data, physical assumptions, the approximate solution of the integral-differential equations, etc., will be larger than $\Delta u$. Thus, $\Delta u$ is only one lowest component of a possible mismatch of a real object and its modeling results.

Equating the derivative of $\Delta u / S$ (1) with respect to $z^{\prime}-\beta^{\prime}$ to zero, we obtain the condition for achieving the minimum comparative uncertainty for a particular COP:

$$
\left(z^{\prime}-\beta^{\prime}\right)^{2} /(\Psi-\xi)=\left(z^{\prime \prime}-\beta^{\prime \prime}\right) .
$$

Several remarks should be noted:

1) For mechanics processes $\left(\mathrm{COP}_{\mathrm{SI}} \equiv L M T\right)$, taking into account the aforementioned explanations and (4), the lowest comparative uncertainty $\varepsilon_{L M T}$ can be reached at the following conditions:

$$
\begin{gathered}
\left(z^{\prime}-\beta^{\prime}\right)=\left(e_{l} \cdot e_{m} \cdot e_{t}-1\right) / 2-3=(7 \cdot 3 \cdot 9-1) / 2-3=91, \\
\left(z^{\prime \prime}-\beta^{\prime \prime}\right)=\left(z^{\prime}-\beta^{\prime}\right)^{2} /(\Psi-\xi)=94^{2} / 38,265=0.2164<1,
\end{gathered}
$$

where " -1 " corresponds to the case when all the primary variable exponents are zero in formula (2); dividing by 2 indicates that there are direct and inverse variables, e.g., $L^{1}$-length, $L^{-1}$-run length, and 3 corresponds to the three primary variables $L, M, T$.

According to (1) $\varepsilon_{L M T}$ equals

$$
\varepsilon_{L M T}=(\Delta u / S)_{L M T}=91 / 38,265+0.2164 / 91=0.0048 .
$$

In other words, according to (9), even one DS main variable does not allow one to reach the lowest comparative uncertainty. Therefore, in the frame of the suggested approach, nobody can realize the original first-born comparative uncertainty using any mechanistic model $\left(\mathrm{COP}_{\mathrm{SI}} \equiv L M T\right)$. Moreover, the greater the number of mechanical parameters, the greater the first-born embedded uncertainty. In other words, for example, the Cavendish method, in the frame of the suggested approach, is not recommended for measurements of the Newtonian gravitational constant.

Such statements appear to be highly controversial, and one might even say, very unprofessional, not credible and far from current reality. However, as we shall see below, the proposed approach allows the obvious conclusions not to be made, consistent with practice.

2) For electromagnetism processes $\left(\mathrm{COP}_{\mathrm{SI}} \equiv L M T 1\right)$, taking into account (4), the lowest comparative uncertainty can be reached at the following conditions:

$$
\begin{gathered}
\left(z^{\prime}-\beta^{\prime}\right)=\left(e_{l} \cdot e_{m} \cdot e_{t} \cdot e_{i}-1\right) / 2-4=(7 \times 3 \times 9 \times 5-1) / 2-4=468, \\
\left(z^{\prime \prime}-\beta^{\prime \prime}\right)=\left(z^{\prime}-\beta^{\prime}\right)^{2} /(\Psi-\xi)=468^{2} / 38,265 \approx 5.723873
\end{gathered}
$$

where " -1 " corresponds to the case when all the primary variable exponents are zero in formula (2); dividing by 2 indicates that there are direct and inverse variables, e.g., $L^{1}$-length, $L^{-1}$-run length, and 4 corresponds to the four primary variables $L, M, T, I$.

Then, one can calculate the minimum achievable comparative uncertainty 
$\varepsilon_{L M T I}$

$$
\begin{aligned}
\varepsilon_{\text {LMTI }} & =(\Delta u / S)_{\text {LMTI }}=468 / 38,265+5.723873 / 468 \\
& =0.0122+0.0122=0.0244 .
\end{aligned}
$$

3) For combined heat and electromagnetism processes $\left(\mathrm{COP}_{\mathrm{SI}} \equiv L M T \theta I\right)$, taking into account (4), the lowest comparative uncertainty $\varepsilon_{\text {LMTI }}$ can be reached at the following conditions:

$$
\begin{gathered}
\left(z^{\prime}-\beta^{\prime}\right)=\left(e_{1} \cdot e_{m} \cdot e_{t} \cdot e_{\theta} \cdot e_{i}-1\right) / 2-5=(7 \times 3 \times 9 \times 9 \times 5-1) / 2-5=4247, \\
\left(z^{\prime \prime}-\beta^{\prime \prime}\right)=\left(z^{\prime}-\beta^{\prime}\right)^{2} /(\Psi-\xi)=4247^{2} / 38,265 \approx 471 .
\end{gathered}
$$

where " -1 " corresponds to the case when all the primary variable exponents are zero in formula (2); dividing by 2 indicates that there are direct and inverse variables, e.g., $L^{1}$-length, $L^{-1}$-run length, and 5 corresponds to the three primary variables $L, M, T, \Theta, I$.

Then one can calculate the minimum achievable comparative uncertainty $\varepsilon_{\text {LMT } \theta I}$

$$
\begin{aligned}
\varepsilon_{\text {LмтөI }} & =(\Delta u / S)_{\text {LмтөI }}=4247 / 38,265+471 / 4247 \\
& =0.1110+0.1109=0.2219
\end{aligned}
$$

4) For heat processes $\left(\mathrm{COP}_{\mathrm{SI}} \equiv L M T \theta\right)$, taking into account (4), the lowest comparative uncertainty $\varepsilon_{\text {LMTO }}$ can be reached at the following conditions

$$
\begin{gathered}
\left(z^{\prime}-\beta^{\prime}\right)=\left(e_{1} \cdot e_{m} \cdot e_{t} \cdot e_{\theta}-1\right) / 2-4=(7 \times 3 \times 9 \times 9-1) / 2-4=846, \\
\left(z^{\prime \prime}-\beta^{\prime \prime}\right)=\left(z^{\prime}-\beta^{\prime}\right)^{2} /(\Psi-\xi)=846^{2} / 38,265 \approx 19 .
\end{gathered}
$$

where " -1 " corresponds to the case when all the primary variable exponents are zero in formula (2); dividing by 2 indicates that there are direct and inverse variables, e.g., $L^{1}$-length, $L^{-1}$-run length, and 4 corresponds to the four primary variables $L, M, T, \Theta$.

Then one can calculate the minimum achievable comparative uncertainty $\varepsilon_{L M T \theta}$

$$
\begin{aligned}
\varepsilon_{\text {LMT } \theta} & =(\Delta u / S))_{\text {LMT } \theta}=846 / 38,265+19 / 846 \\
& =0.0221+0.0221=0.0442 .
\end{aligned}
$$

Let us now try to apply the aforementioned method for the analysis of the accuracy of some physical laws, and determine the minimum possible, relative, measurement uncertainty of several fundamental physical constants.

\section{Applications}

\subsection{Law of Gravitation}

According to the law of universal gravitation, which is the greatest generalization achieved by the human mind, two bodies act on each other with a force that is inversely proportional to the square of the distance between them, and directly proportional to the product of their masses. The coefficient of proportionality is the gravitational constant $G$. Then, in accordance with the theory of measurement, the total absolute measurement uncertainty of force will be greater than 
the uncertainty of each variable included in this formula. In this case, we could draw the following conclusion. If we can find out the value of the smallest uncertainty in the measurement of the gravitational constant, then we could declare the appropriate experimental accuracy in the determination of the forces of attraction in the law of gravitation.

In [7], scientific publications and CODATA (Committee on Data for Science and Technology) recommendations over the past 15 years (2000-2014) were discussed from the position of the reached relative and comparative uncertainties values. In none of the current experiments of the calculation of Newtonian gravitational constant value was the prospective interval not declared, in which its true value could be placed. In other words, the exact trace of the placement of $G$ is lost somewhere. Therefore, in order to apply the stated approach, as a possible measurement interval of the Newtonian gravitational constant, we chose the difference of its value attained by the experimental results of two projects: $G_{\text {min }}=6.6719199 \times 10^{-11} \mathrm{~m}^{3} \cdot \mathrm{kg}^{-1} \cdot \mathrm{s}^{-2} \quad[8]$ and $G_{\max }=6.6755927 \times 10^{-11} \mathrm{~m}^{3} \cdot \mathrm{kg}^{-1} \cdot \mathrm{s}^{-2}$ [9]. Then, the possible observed range $S^{*}$ of $G$ variations equals

$$
\begin{aligned}
S^{*} & =G_{\max }-G_{\min }=6.6755927 \times 10^{-11}-6.6719199 \times 10^{-11} \\
& =3.6728 \times 10^{-14}\left(\mathrm{~m}^{3} \cdot \mathrm{kg}^{-1} \cdot \mathrm{s}^{-2}\right) .
\end{aligned}
$$

The obtained data are summarized in Table 1. Judging the data by the relative

Table 1. Summary of the partial history of Newtonian gravitational constant measurements in terms of reaching its value, and

\begin{tabular}{|c|c|c|c|c|c|c|c|}
\hline \multirow{3}{*}{ No } & \multirow{3}{*}{ Year } & $\begin{array}{c}\text { Gravitational } \\
\text { constant }\end{array}$ & $\begin{array}{c}\text { Relative } \\
\text { uncertainty }\end{array}$ & $\begin{array}{c}\text { Absolute } \\
\text { uncertainty }\end{array}$ & $\begin{array}{l}\text { G changes } \\
\text { range }\end{array}$ & $\begin{array}{c}\text { Reached comparative } \\
\text { uncertainty }\end{array}$ & \multirow{3}{*}{ Ref. } \\
\hline & & $G \times 10^{11}$ & \multirow{2}{*}{$r_{G} \times 10^{5}$} & $\Delta_{G} \times 10^{15}$ & $S_{G} \times 10^{14}$ & \multirow{2}{*}{$\varepsilon=\Delta_{G} / S_{G} \times 10^{2}$} & \\
\hline & & $\mathrm{m}^{3} \cdot \mathrm{kg}^{-1} \cdot \mathrm{s}^{-2}$ & & $\mathrm{~m}^{3} \mathrm{~kg}^{-1} \mathrm{~s}^{-2}$ & $\mathrm{~m}^{3} \cdot \mathrm{kg}^{-1} \cdot \mathrm{s}^{-2}$ & & \\
\hline 1 & 2000 & 6.674256 & 1.4 & 0.934396 & & 2.5441 & [10] \\
\hline 2 & 2001 & 6.675593 & 4.0 & 2.670237 & & 7.2703 & [9] \\
\hline 3 & 2002 & 6.674230 & 15 & 10.01134 & & 27.2581 & [11] \\
\hline 4 & 2002 & 6.674072 & 3.3 & 2.202444 & & 5.9966 & [12] \\
\hline 5 & 2002 & 6.674210 & 15 & 10.01132 & & 27.2580 & [13] \\
\hline 6 & 2003 & 6.673873 & 4.0 & 2.669549 & & 7.2684 & [14] \\
\hline 7 & 2006 & 6.674251 & 1.9 & 1.268108 & & 3.4527 & [15] \\
\hline 8 & 2008 & 6.674287 & 10 & 6.674287 & 3.6728 & 18.1722 & [16] \\
\hline 9 & 2009 & 6.673492 & 2.7 & 1.801843 & & 4.9059 & [17] \\
\hline 10 & 2010 & 6.672341 & 2.1 & 1.401192 & & 3.8150 & [18] \\
\hline 11 & 2010 & 6.673848 & 12 & 8.008618 & & 21.8052 & [19] \\
\hline 12 & 2014 & 6.675542 & 2.5 & 1.668886 & & 4.5439 & [20] \\
\hline 13 & 2014 & 6.674083 & 4.7 & 3.136819 & & 8.5408 & [21] \\
\hline 14 & 2014 & 6.671920 & 15 & 10.00788 & & 27.2486 & [8] \\
\hline
\end{tabular}
absolute, relative and comparative uncertainties. 
and comparative uncertainties, one can see that the measurement accuracy had not significantly changed during the last 15 years. It should be noted that the relationship between relative uncertainty $r_{G}$ and absolute uncertainty $\Delta_{G}$ is the following

$$
r_{G}=\Delta_{G} / G \text {. }
$$

According to these data, the development of a larger number of designs and improvement of the various experimental facilities for the measurement of the gravitational constant using schemes combining a torsion balance and electromagnetic equipment is an absolute must in order to achieve results closer to the minimum comparative uncertainty $\left(\varepsilon_{\min }\right)_{L M T I}$ for the class of phenomena $\mathrm{COP}_{\mathrm{SI}} \equiv L M T I$, for which the comparative uncertainty equals 0.0246 (19). This is explained by the fact (Section 2) that nobody can realize the original firstborn comparative uncertainty using any mechanistic model ( $\left.\mathrm{COP}_{\mathrm{SI}} \equiv L M T\right)$. In addition, we calculated the lowest relative uncertainty $\left(r_{\min }\right)_{L M T I}$ for $\mathrm{COP}_{\mathrm{SI}}$ $\equiv$ LMTI, which equals $1.4 \times 10^{-5}$. This is in excellent agreement with the recommendations mentioned in [14] $1.4 \times 10^{-5}$. Thus, the use of the $\aleph_{\text {SI }}$-hypothesis and the concept of comparative uncertainty allow us to give recommendations on which direction to carry out experimental investigations and identify achievable minimum relative uncertainty in the calculations of the gravitational law in classical mechanics. At the same, an estimated value of comparative uncertainty allows only for better calculations, but does not change our understanding of gravity.

\subsection{Heisenberg's Uncertainty Relation}

We have applied the $\aleph_{\mathrm{SI}}$-hypothesis for a novel theoretical evaluation of Heisenberg's uncertainty relation in one-dimensional space based on a mathematical formulation of the comparative uncertainty.

The theoretical limit of accuracy of any measurements for the DL standard deviation of coordinates $\Delta x$ (uncertainty of position) and DL standard deviation of the momentum $\Delta p$ (uncertainty of momentum) is the following

$$
\Delta x \cdot \Delta p \geq \hbar / 2 \text {, }
$$

where $\hbar=h /(2 \pi)$, and $h$ denotes Planck's constant.

We can obtain:

$$
\begin{aligned}
& \Delta X / S_{x} \leq\left(z^{\prime}-\beta^{\prime}\right) / \aleph_{\mathrm{SI}}+\left(z^{\prime \prime}-\beta^{\prime \prime}\right) /\left(z^{\prime}-\beta^{\prime}\right), \\
& \Delta P / S_{p} \leq\left(z^{\prime}-\beta^{\prime}\right) / \aleph_{\mathrm{SI}}+\left(z^{\prime \prime}-\beta^{\prime \prime}\right) /\left(z^{\prime}-\beta^{\prime}\right),
\end{aligned}
$$

where $\Delta X$ denotes the DS standard deviation of coordinate $X, \Delta P$ denotes the DS uncertainty of the DS momentum $P, S_{x}$ denotes the DS considered range of changes of the measured DS variable $X, S_{p}$ denotes the DS considered range of changes of the DS momentum $P$.

Equation (22) and Equation (23) are realized due to the following

$$
\Delta x / S_{x}^{*}=\left(\Delta x / r^{*}\right) /\left(S_{x}^{*} / r^{*}\right)=\Delta X / S_{x},
$$

or 


$$
\Delta x / \Delta X=S_{x}^{*} / S_{x},
$$

where $S_{x}^{*}$ is the DL considered range of changes of the measured DL variable $x, S_{x}$ denotes the DS considered range of changes of the measured DS variable $X, r^{*}$ denotes the DL scale parameter with the same dimension that $X$ and $S_{x}^{*}$ have, and $\Delta X$ denotes the DS standard deviation of coordinate $X$.

And $\left(\varepsilon_{\text {min }}\right)_{L M T}$ equals

$$
\begin{aligned}
& \left(\varepsilon_{x \min }\right)_{L M T}=91 / 38,265+0.216412 / 91=0.004756, \\
& \left(\varepsilon_{p \min }\right)_{L M T}=91 / 38,265+0.216412 / 91=0.004756,
\end{aligned}
$$

where $\left(\varepsilon_{x \min }\right)_{L M T}$ and $\left(\varepsilon_{p \min }\right)_{L M T}$ are minimum comparative uncertainties, respectively, of DS variables $X$ and $P$.

Then

$$
\begin{aligned}
& \Delta X / S_{x} \leq 0.004756, \\
& \Delta P / S_{p} \leq 0.004756,
\end{aligned}
$$

Taking into account (28) and (29),

$$
\begin{aligned}
\Delta x \cdot \Delta p & =S_{p}^{*} \cdot S_{p}^{*} \times 0.004756^{2} \\
& =S_{x}^{*} \cdot S_{p}^{*} \times 0.0000236 \geq \hbar / 2,
\end{aligned}
$$

where $S_{p}^{*}$ is the DL considered range of changes of the measured DL variable $p$.

Then the modified Heisenberg's uncertainty relation for one-dimensional space can be introduced with a relative uncertainty of $9 \times 10^{-6}$ in the following form

$$
\begin{aligned}
S_{x}^{*} \cdot S_{p}^{*} & \geq 44,203.90729 \cdot \hbar \approx \aleph_{S I} \cdot(2 \cdot \gamma+1.4 \beta) \cdot \hbar \\
& =\left(\alpha^{-1}+\mathrm{e}^{0.25}\right)^{2} \cdot(2 \gamma+1.4 \beta) \cdot \hbar,
\end{aligned}
$$

where $\hbar=h /(2 \pi)$, and $h$ denotes Planck's constant, $\hbar=1.054572 \times 10^{-34} \mathrm{~m}^{2} \cdot \mathrm{kg} \cdot \mathrm{s}^{-2}, \alpha$ is the fine structure constant, $\alpha^{-1}=137.035999 \quad[22], \gamma$ is Euler's constant, 0.577216; $\beta=1 / 1,836.152746, \beta=m_{e} / m_{p}, \quad m_{\mathrm{e}}$ is the electron mass, $9.109383 \times 10^{-31} \mathrm{~kg}$, and $m_{p}$ is the proton mass, $1.672622 \times 10^{-27} \mathrm{~kg}$ [4].

The modified theoretical limit of accuracy of any measurements connects the DL considered range of changes of the measured DL variable $\boldsymbol{x}$ and the DL considered range of changes of the measured DL variable $\boldsymbol{p}$. According to the aforementioned investigation the expression $S_{x}^{*} \cdot S_{p}^{*}$ (31) can be regarded as a first approximation, as a real constant in space and time because its value depends essentially on $\alpha, \mathrm{e}, \gamma, \beta$ and $\hbar$.

This Equation (31) is objective and independent from the presence of the conscious observer conducting measurements. Thus, according to equation (36) the interval of the particle location and the interval of the particle momentum cannot be known with absolute precision simultaneously. The more precisely one specifies the location of the particle, the larger the degree of uncertainty of 
the particle's momentum, and vice versa.

Equation (31) is in fact a possible interpretation of a general principle of W. Heisenberg (21) in another form, which holds for any investigated object. At the same time, it is understood that without enough comparison with previous results, the readers cannot evaluate whether the introduced results are good or bad. That is why further examples, maybe, can convince researchers for the appropriateness of the $\aleph$-hypothesis for experiments in engineering and physics.

\subsection{Fine Structure Constant}

The desire to measure the fine-structure constant $\alpha$ with a great accuracy has gained paramount importance, because $\alpha$ is directly connected to the problem of understanding the physical nature of elementary particles; it appears not to be separated from them, and is their depth property.

Analyses of the fine structure constant measurements during 2006-2014 were realized. Principles of research and treatment of results are similar to the scheme set out in Chapter 3.1. The data are summarized in Table 2 and Figure 1.

The fact is that the measurement accuracy of $\alpha$ has not significantly changed during the last nine years in terms of the attained relative $r_{\alpha}$ and comparative $\Delta_{\alpha} / S_{\alpha}$ uncertainties. We calculated the recommended value of the relative uncertainty $\left(r_{\alpha \min }\right)_{L M T}=2.9 \times 10^{-11}$ for $\mathrm{COP}_{\mathrm{SI}} \equiv L M T$, for which the comparative uncertainty equals $0.0049(10)$. This value is one order of magnitude lower than the value recommended in [31] $\left(2.3 \times 10^{-10}\right)$, and can be used to refine $\alpha$ value further. However, as noted in Chapter 2, due to the principle inaccessibility to realize/reach the minimum comparative uncertainty in $\mathrm{COP}_{\mathrm{SI}} \equiv L M T$, future research should be focused on the development of pilot schemes and test benches, corresponding, for example, to $\mathrm{COP}_{\mathrm{SI}} \equiv L M T \Theta$ or $\mathrm{COP}_{\mathrm{SI}} \equiv L M T I$.

Table 2. Results of the fine structure constant measurements during 2006-2014 in terms of attaining its value, and absolute, relative and comparative uncertainties.

\begin{tabular}{|c|c|c|c|c|c|c|c|}
\hline \multirow[t]{2}{*}{ No. } & \multirow[t]{2}{*}{ Year } & $\begin{array}{c}\text { FSC } \\
\text { reverse value }\end{array}$ & $\begin{array}{c}\text { Relative } \\
\text { uncertainty }\end{array}$ & $\begin{array}{l}\text { Absolute } \\
\text { uncertainty }\end{array}$ & $\alpha$ range & $\begin{array}{c}\text { Comparative } \\
\text { uncertainty }\end{array}$ & \multirow[t]{2}{*}{ Ref. } \\
\hline & & $1 / \alpha$ & $r_{\alpha} \cdot 10^{9}$ & $\Delta_{\alpha} \cdot 10^{7}$ & $S_{\alpha} \cdot 10^{7}$ & $\Delta_{\alpha} / S_{\alpha}$ & \\
\hline 1 & 2006 & 137.035999680 & 0.68 & 0.931844798 & & 0.1117 & [16] \\
\hline 2 & 2007 & 137.035999071 & 71.0 & 97.2955593 & & 0.1167 & [23] \\
\hline 3 & 2008 & 137.035999085 & 0.37 & 0.507033197 & & 0.0608 & [24] \\
\hline 4 & 2008 & 137.035999252 & 1.00 & 1.37035999 & & 0.1643 & [25] \\
\hline 5 & 2010 & 137.035999074 & 0.32 & 0.438515197 & & 0.0526 & [19] \\
\hline 6 & 2011 & 137.035999038 & 0.66 & 0.904437594 & 8.34 & 0.1084 & [26] \\
\hline 7 & 2011 & 137.035999456 & 4.60 & 6.30365597 & & 0.7558 & [27] \\
\hline 8 & 2012 & 137.035999173 & 0.25 & 0.342589998 & & 0.0411 & [28] \\
\hline 9 & 2013 & 137.035999872 & 2.00 & 2.74072000 & & 0.3286 & [29] \\
\hline 10 & 2014 & 137.035999139 & 0.23 & 0.315182798 & & 0.0378 & [30] \\
\hline
\end{tabular}




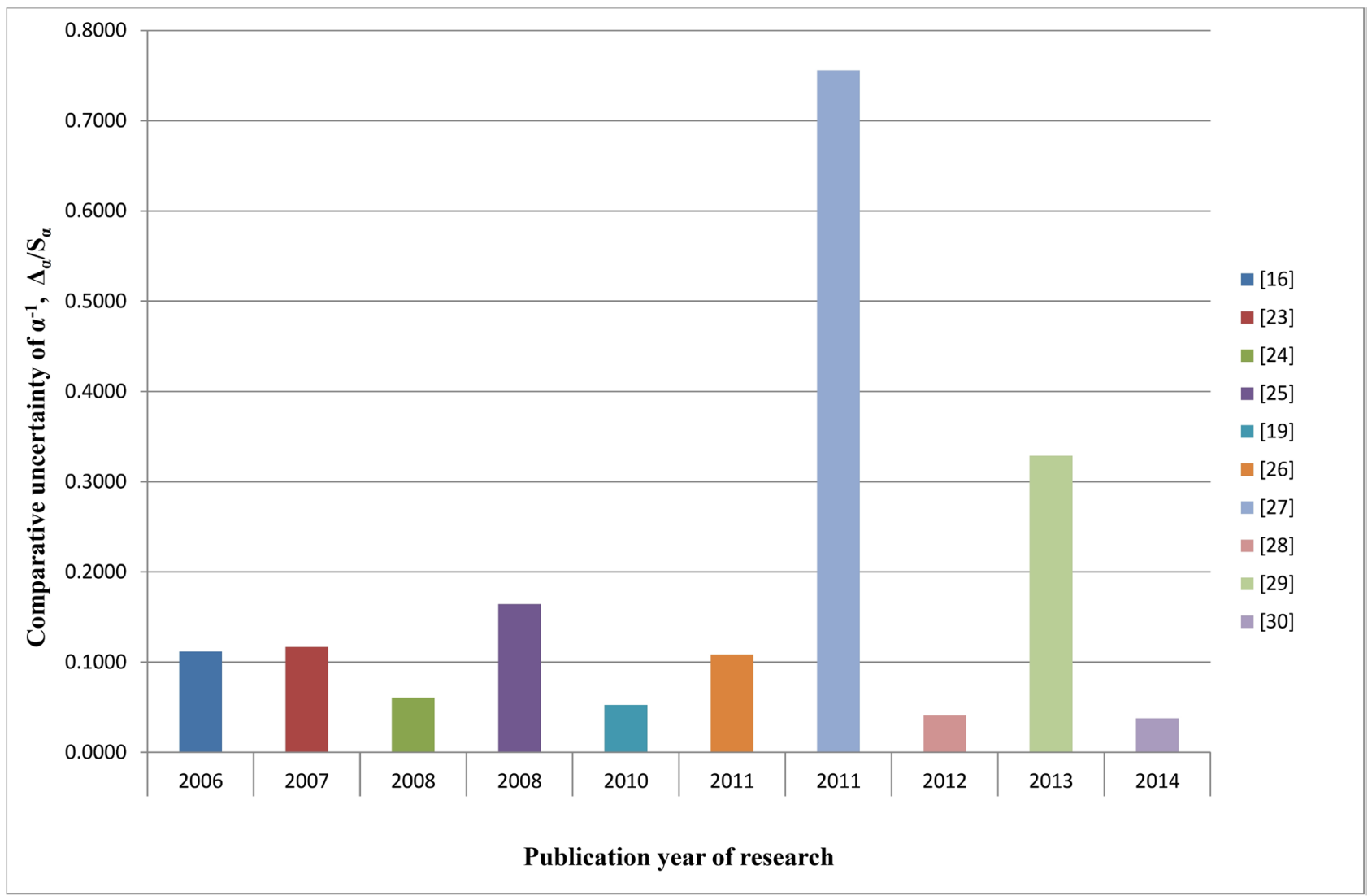

Figure 1. Graph summarizing the partial history of fine structure constant measurement, displaying the changes of comparative uncertainty.

\subsection{Plank's Constant}

The great importance of the Planck's constant in modern physics causes a situation where many studies have been dedicated to its measurement [32] [33]. However, the experiment results show discrepancies.

We analyzed several scientific publications of 2007-2014 from the position of the attained relative and comparative uncertainties values following the same scheme that is introduced in Chapter 3.1. The data are summarized in Table 3.

It can be argued that, according to the results presented, as in the case of the gravitational constant and the fine structure constant measurements, the accuracy of measurements of Planck's constant has not improved significantly over the past seven years. All studies were conducted as part of $\mathrm{COP}_{\text {SI }} \equiv L M T I$. The minimum comparative uncertainty equal to 0.0244 (13) was not achieved. According to data of Table 3 , there is calculated an attainable value of the relative uncertainty $r_{h \min }$ equaled $8.7 \times 10^{-9}$. Yet this is almost four times lower than the relative uncertainty value mentioned in [32]: $35 \times 10^{-9}$. Thus, questions remain unanswered. Nevertheless, it is hoped that $r_{h \min }$ could be satisfactory for the existing mass standards community.

\subsection{Boltzmann Constant}

The analysis of the Boltzmann constant $k_{b}$ plays an increasingly important role 
Table 3. Results of Planck's constant measurements during 2007-2014 in terms of having attained its value, and absolute, relative and comparative uncertainties.

\begin{tabular}{|c|c|c|c|c|c|c|c|c|}
\hline \multirow{3}{*}{ No. } & \multirow{3}{*}{ Year } & \multirow{3}{*}{ Method } & \multirow{3}{*}{$\begin{array}{c}\begin{array}{c}\text { Planck's } \\
\text { constant value }\end{array} \\
h \cdot 10^{34} \\
\mathrm{~m}^{2} \cdot \mathrm{kg} \cdot \mathrm{s}^{-2}\end{array}$} & \multirow{3}{*}{$\begin{array}{c}\text { Relative } \\
\text { uncertainty } \\
r_{h} \cdot 10^{7}\end{array}$} & \multirow{3}{*}{$\begin{array}{c}\begin{array}{c}\text { Absolute } \\
\text { uncertainty }\end{array} \\
\Delta_{h} \cdot 10^{41} \\
\mathrm{~m}^{2} \cdot \mathrm{kg} \cdot \mathrm{s}^{-2}\end{array}$} & \multirow{2}{*}{$\begin{array}{l}\alpha \text { range } \\
S_{h} \cdot 10^{40}\end{array}$} & \multirow{3}{*}{$\begin{array}{c}\text { Comparative } \\
\text { uncertainty } \\
\Delta_{h} / S_{h}\end{array}$} & \multirow{3}{*}{ Ref. } \\
\hline & & & & & & & & \\
\hline & & & & & & $\mathrm{m}^{2} \cdot \mathrm{kg} \cdot \mathrm{s}^{-2}$ & & \\
\hline 1 & 2007 & NIST watt balance & 6.626068912 & 0.36 & 2.38538481 & & 0.1037 & [34] \\
\hline 2 & 2007 & NPL watt balance & 6.626071213 & 2.0 & 13.2521424 & & 0.5762 & [35] \\
\hline 3 & 2010 & CODATA & 6.626069573 & 0.44 & 2.91547061 & & 0.1268 & [19] \\
\hline 4 & 2011 & METAS watt balance & 6.626069120 & 2.9 & 19.2156004 & 2.3 & 0.8355 & [36] \\
\hline 5 & 2011 & N-Avog & 6.626070000 & 0.30 & 1.98782102 & & 0.0863 & [37] \\
\hline 6 & 2014 & NIST watt balance & 6.626069793 & 0.45 & 2.98173141 & & 0.1296 & [38] \\
\hline 7 & 2014 & NRC watt balance & 6.626070341 & 0.14 & 0.95415413 & & 0.0415 & [39] \\
\hline
\end{tabular}

in our physics today to ensure the correct contribution to the next CODATA value and to the new definition of the Kelvin. This task is more difficult and crucial when its true-target value is not known. This is the case for any methodologies intended to look at the problem from a possible another view, and which, maybe, have different constraints and need special discussion.

Analysis of the Boltzmann constant measurements made during 2007-2015 shows that none of the current experimental measurements that calculate $\mathrm{k}_{\mathrm{b}}$ have declared an uncertainty interval in which the true value can be placed. Therefore, in order to apply the stated approach, as the estimated interval of $k_{b}$ changes, we choose the difference of its value reached by the experimental results of two projects: $k_{b \max }=1.38065511 \times 10^{-23} \mathrm{~m}^{2} \cdot \mathrm{kg} /\left(\mathrm{s}^{2} \cdot \mathrm{K}\right) \quad[40]$ and $k_{b \min }=1.380640 \times 10^{-23} \mathrm{~m}^{2} \cdot \mathrm{kg} /\left(\mathrm{s}^{2} \cdot \mathrm{K}\right)$ [41]. In this case, the possible observed range $S_{k}$ of $k_{b}$ variation is equal to

$$
\begin{aligned}
S_{k} & =k_{b \max }-k_{b \min }=1.38065511 \times 10^{-23}-1.3806401 \times 10^{-23} \\
& =1.501 \times 10^{-28} \mathrm{~m}^{2} \cdot \mathrm{kg} /\left(\mathrm{s}^{2} \cdot \mathrm{K}\right)
\end{aligned}
$$

Following the same line of reasoning that was introduced in Sections 3.3 and 3.4, and taking into account (22), we analyzed several scientific publications and CODATA recommendations over six years from the perspective of the achieved relative and comparative uncertainties values. The data are summarized in Table 4 and Figures 2-4. By analyzing theoretical methods and experimental schemes, one can declare that results were obtained using $\mathrm{COP}_{\mathrm{SI}} \equiv L M T \Theta$ or $\mathrm{COP}_{\mathrm{SI}} \equiv$ LMT I.

It can be seen from the data given in Table 4 and Figures 2-4 that a dramatic improvement in the accuracy of measurement of the Boltzmann constant has not been achieved during the last decade, judging the data by both relative and comparative uncertainties and two different $\mathrm{COP}_{\mathrm{SI}}: L M T \Theta, L M T \Theta I$. Despite the fact that the authors of the mentioned studies stated on account of all possible sources of error, the value of the absolute and relative uncertainties can differ by 
Table 4. Results of Boltzmann's constant measurements during 2007-2012 in terms of its value attained, and absolute, relative and comparative uncertainties.

\begin{tabular}{|c|c|c|c|c|c|c|c|c|}
\hline \multirow{3}{*}{ No } & \multirow{3}{*}{ Year } & \multirow{3}{*}{ COP } & $\begin{array}{c}\text { Boltzmann } \\
\text { constant }\end{array}$ & $\begin{array}{l}\text { Relative } \\
\text { uncertainty }\end{array}$ & $\begin{array}{l}\text { Absolute } \\
\text { uncertainty }\end{array}$ & $\begin{array}{l}k_{\mathrm{b}} \text { changes } \\
\text { range }\end{array}$ & $\begin{array}{c}\text { Reached comparative } \\
\text { uncertainty }\end{array}$ & \multirow{3}{*}{ Ref. } \\
\hline & & & $k_{\mathrm{b}} \cdot 10^{23}$ & \multirow{2}{*}{$r_{K b} \cdot 10^{29}$} & $\Delta_{K b} \cdot 10^{28}$ & $S_{K b} \cdot 10^{28}$ & \multirow{2}{*}{$\varepsilon_{K b}=\Delta_{K b} / S_{K b}$} & \\
\hline & & & $\mathrm{m}^{2} \cdot \mathrm{kg} /\left(\mathrm{s}^{2} \cdot \mathrm{K}\right)$ & & $\mathrm{m}^{2} \cdot \mathrm{kg} /\left(\mathrm{s}^{2} \cdot \mathrm{K}\right)$ & $\mathrm{m}^{2} \cdot \mathrm{kg} /\left(\mathrm{s}^{2} \cdot \mathrm{K}\right)$ & & \\
\hline 1 & 2007 & $L M T \theta I$ & 1.380653 & 9.1 & 12.56394 & & 0.8370382 & [42] \\
\hline 2 & 2009 & $L M T \theta$ & 1.380650 & 2.7 & 3.727754 & & 0.2483513 & [43] \\
\hline 3 & 2010 & $L M T \theta$ & 1.380640 & 7.5 & 10.35480 & & 0.6898601 & [41] \\
\hline 4 & 2010 & $L M T \theta$ & 1.380650 & 3.1 & 4.280014 & & 0.2851442 & [44] \\
\hline 5 & 2011 & $L M T \theta$ & 1.380648 & 1.2 & 1.656777 & & 0.1103782 & [45] \\
\hline 6 & 2011 & $L M T \theta$ & 1.380652 & 12 & 16.56783 & 1.50 & 1.1037860 & [46] \\
\hline 7 & 2011 & $L M T \theta$ & 1.380655 & 7.9 & 10.90717 & & 0.7266605 & [47] \\
\hline 8 & 2012 & $L M T \theta$ & 1.380655 & 7.9 & 10.90718 & & 0.7266606 & [40] \\
\hline 9 & 2012 & -- & 1.380649 & 0.91 & 1.256390 & & 0.0837036 & [19] \\
\hline 10 & 2014 & -- & 1.380649 & 0.57 & 0.7869697 & & 0.0524297 & [48] \\
\hline 11 & 2015 & $L M T \theta I$ & 1.380651 & 3.9 & 5.384540 & & 0.3587302 & [49] \\
\hline
\end{tabular}

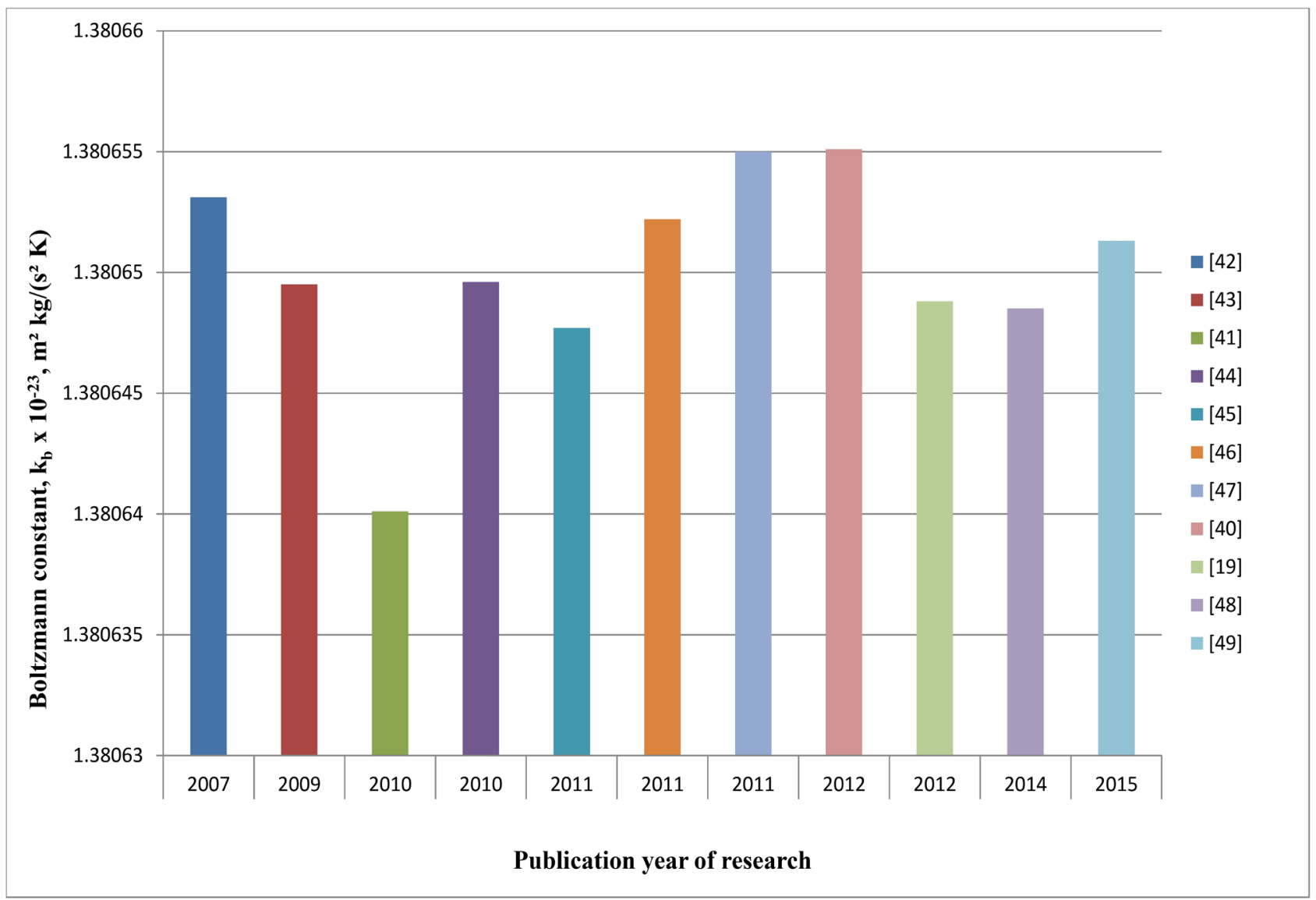

Figure 2. Graph summarizing the partial history of Boltzmann constant measurement. 


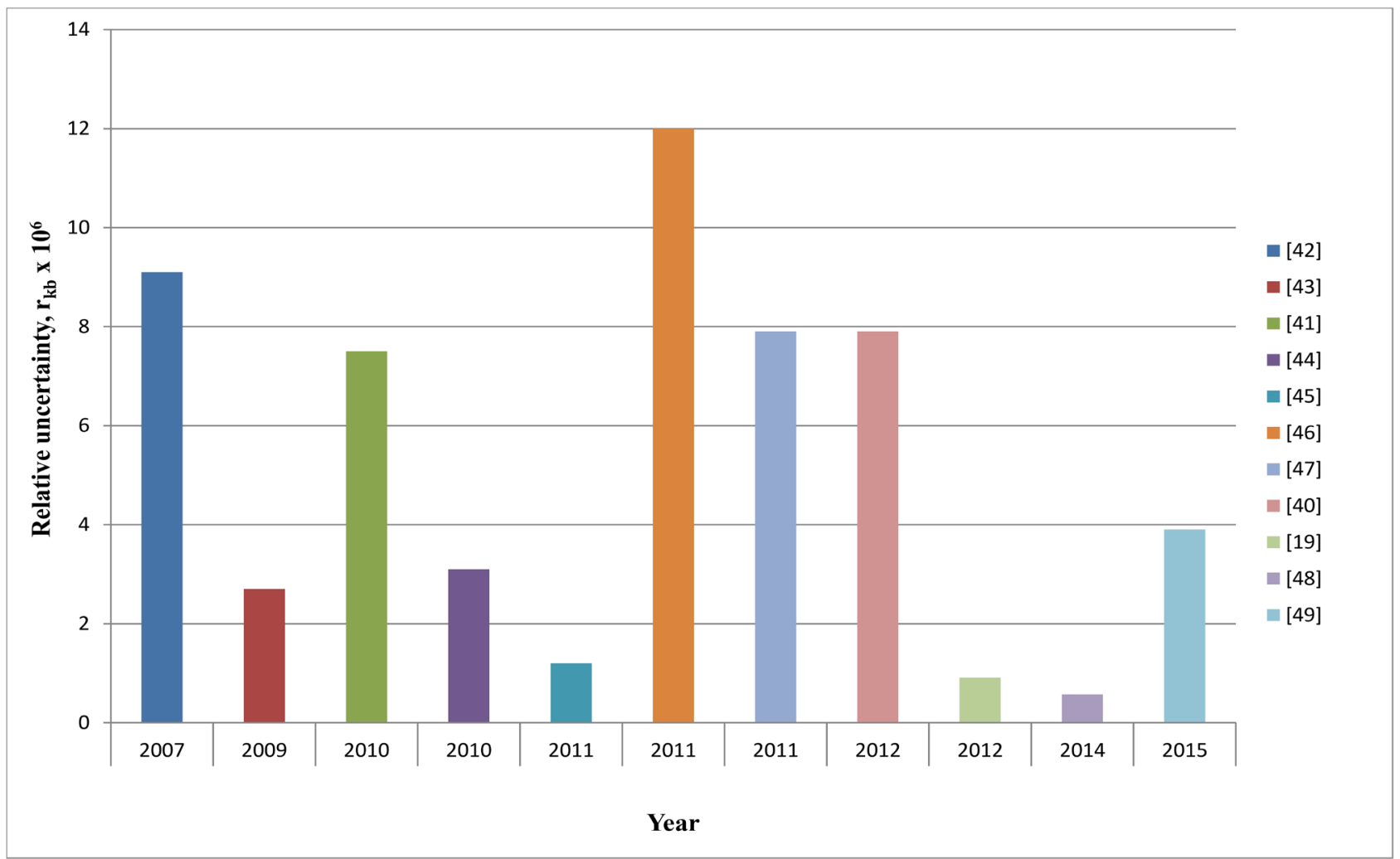

Figure 3. Graph summarizing the partial history of Boltzmann constant measurement, displaying changes in the relative uncertainty.

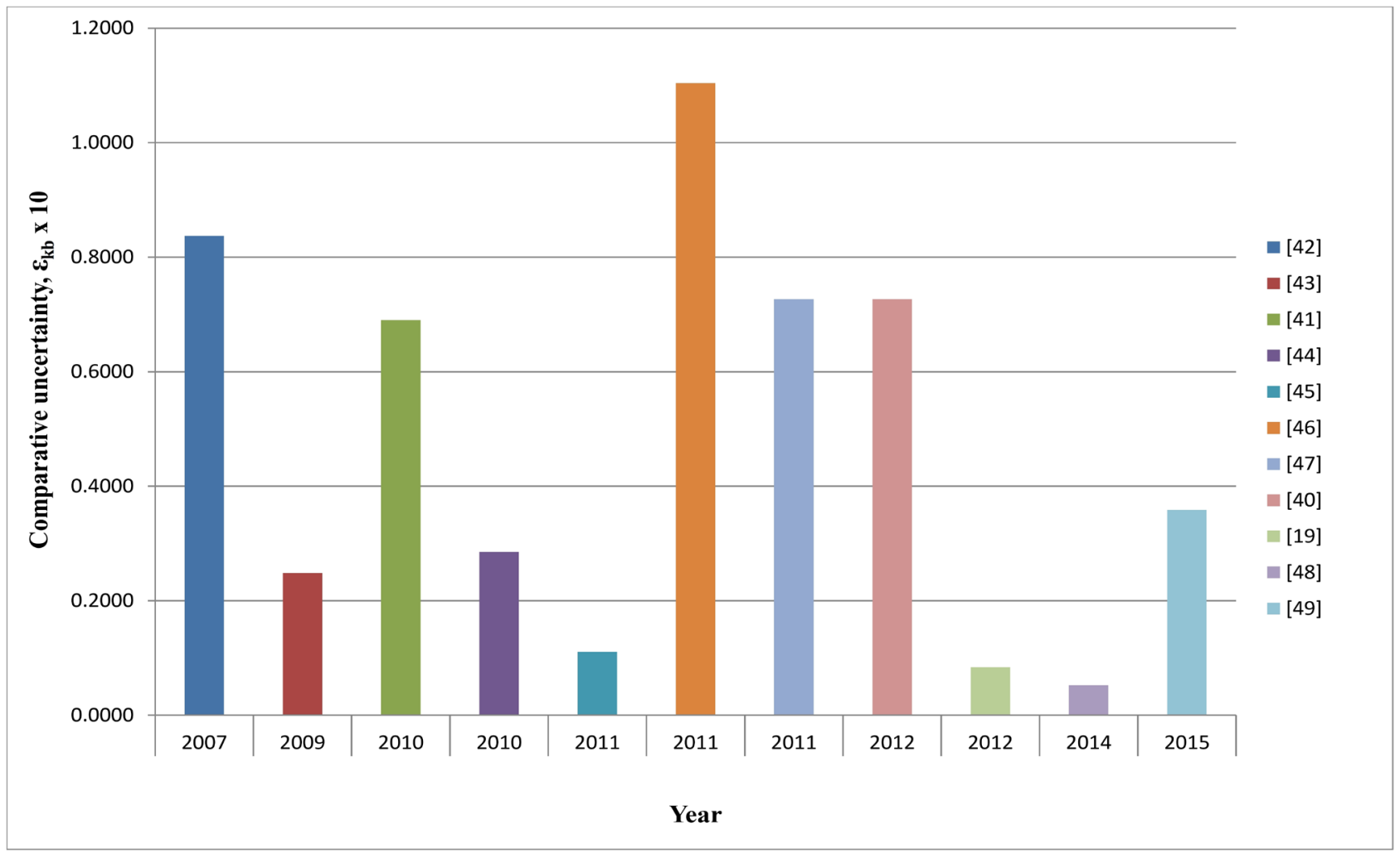

Figure 4. Graph summarizing the partial history of Boltzmann constant measurement displaying changes in the comparative uncertainty. 
more than twenty times. A similar situation exists for the spread of the value of the comparative uncertainty. Without going into analysis of the uncertainties nature, a part of which the researchers have already identified, we can say with great confidence that, under the proposed approach, one of the reasons for the created unsatisfactory situation is a number of variables taken into account in the measurement or the chosen model for calculation of the Boltzmann constant. So, for $\mathrm{COP}_{\mathrm{SI}} \equiv L M T \Theta$, in order to achieve the minimum comparative uncertainty there must be taken into account 19 variables (18), and for $\mathrm{COP}_{\mathrm{SI}} \equiv$ $L M T \Theta I$ already 471 (15) variables. In all these works the number of variables taken into account is much smaller. Thus, to improve the accuracy of measurement of the Boltzmann constant there need to complicate experimental stands. To realize this goal, scientists must be prepared to spend sufficient resources.

However, the key data that provide the 2010 recommended value of $k_{b}$ would appear to be close to meeting CODATA requirements [19]. At the same time, the development of a larger number of designs and improvements of various experimental facilities for the measurement of the Boltzmann constant is required in order to bring the results closer to the minimum comparative errors $\left(\varepsilon_{\min }\right)_{\text {LMTE }}$ or $\left(\varepsilon_{\min }\right)_{\text {LMTEI}}$.

We can argue about the order of the desired value of the relative uncertainty of $\mathrm{COP}_{\text {SI }} \equiv L M T \Theta$ that is usually used for measurements of the Boltzmann constant. For this purpose, we take into account the following data:

$\left(\varepsilon_{\text {min }}\right)_{\text {LMT } \theta}=0.0446 \quad(19), \quad S_{k}=1.501 \times 10^{-28} \mathrm{~m}^{2} \cdot \mathrm{kg} /\left(\mathrm{s}^{2} \cdot \mathrm{K}\right) \quad$ (22). Then, the lowest possible absolute uncertainty for $\mathrm{COP}_{\mathrm{SI}} \equiv L M T \Theta$ equals

$$
\begin{aligned}
\left(\Delta_{\min }\right)_{\text {LMT } \theta} & =\left(\varepsilon_{\min }\right)_{L M T \theta} \cdot S_{k}=0.0446 \times 1.501 \times 10^{-28}=0.0669446 \times 10^{-28} S_{k} \\
& =1.501 \times 10^{-28} \mathrm{~m}^{2} \cdot \mathrm{kg} /\left(\mathrm{s}^{2} \cdot \mathrm{K}\right)
\end{aligned}
$$

In this case, the lowest possible relative uncertainty $\left(r_{\min }\right)_{L M T \theta}$ for $\mathrm{COP}_{\mathrm{SI}} \equiv$ $L M T \Theta$ is as follows:

$$
\begin{aligned}
\left(r_{\min }\right)_{L M T \theta} & =\left(\Delta_{\min }\right)_{L_{M T \theta}} /\left(\left(k_{b \max }-k_{b \min }\right) / 2\right) \\
& =0.0669446 \times 10^{-28} / 1.380648 \times 10^{-23}=4.8 \times 10^{-7} .
\end{aligned}
$$

This value is in excellent agreement with the recommendations mentioned in [48] $\left(5.7 \times 10^{-7}\right)$, and can be used for the new definition of the Kelvin and a significant revision of the International System of Units (SI).

\section{Discussion}

Under the proposed approach, for each mathematical model of physical law, there is an uncertainty, which initially, before the full-scale experimental studies, or computer simulations, describes its proximity to the examined physical phenomenon or process. This value is called the comparative uncertainty. It depends only on the number of selected variables and the observation interval of the selected primary variable. One of the interesting features of the proposed hypothesis is that the minimum achievable comparative uncertainty is not constant, and varies depending on the class of phenomena choice. Moreover, theory 
can predict its value. In particular, this means that when switching from a mechanistic model ( $L M T)$ to $\mathrm{COP}$ with a larger number of the primary variables, this uncertainty grows. This change is due to the potential effects of the interaction between the increased number of variables that can or cannot be taken into account by the researcher.

On the one hand, well-known physical laws are valid in a certain area and serve as a reliable tool in everyday life. At the same time, taking into account the experience of the creation of special relativity theory, we know that the achieved accuracy of the description of the world is not satisfactory. On the other hand, fundamental physical constants are currently measured with high accuracy. However, this is not sufficient to be able to modify the International System of Units (SI). The proposed approach allows us to estimate the limits of our knowledge and to reveal an insurmountable barrier for identifying compliance of model and the object studied. Clear evidence of this is the possibility of estimating the minimum attainable value of the relative uncertainty for the gravitational constant, Planck's constant, the fine structure constant, and Boltzmann's constant. In addition, it was possible, to a first approximation, to introduce the Heisenberg inequality for one-dimensional space as a function of the fundamental physical constants, which does not depend on the observer's presence, space and time.

The proposed approach can still not overcome inherent shortcomings, such as:

- This approach is based on the use of interval changes of observed or studied variables. In practice, this parameter is not defined in any serious experimental research in the field of physics. Sometimes, the changes interval of, for example, a gravitational constant, the Boltzmann constant, and other fundamental physical constants, is referred to in review articles only to prove the convergence of the experimental data to a certain value, or to reduce the spread of the results;

- This approach requires the probable appearance of the variables selected by a conscious observer. It ignores factors such as knowledge, intuition, and experience inherent to the researcher. This is why it seems physically impossible;

- The method does not give any recommendations about the selection of specific physical variables, but only imposes a limitation on their number.

Nevertheless, since the proposed method is not associated with the specific structure of the model, which may change, it is more common, simple, and leads to the solution of specific problems, without requiring detailed information about the set of variables. However, the internal mechanism of phenomena is not disclosed.

Qualitative and quantitative conclusions from the relations obtained are consistent with practice. They are as follows:

We conducted a theoretical evaluation of the Heisenberg uncertainty relation, based on the mathematical formulation of the comparative uncertainty. The modified Heisenberg uncertainty relation is introduced, as the first approximation, in a form that depends on only fundamental physical constants. Its value 
does not change in time and space, and is independent of the presence of the conscious observer conducting measurements.

From this study, we can conclude that fundamentally new analysis is an attempt to use comparative uncertainty instead of relative uncertainty in order to verify the accuracy of the physical laws and comparing the results of various measurements of fundamental physical constants. It can be implemented, assuming that their values are within the selected range. However, this idea cannot be proven, because the choice of the interval depends on our previous knowledge, which can be flawed. At the same time, the approach determines the most simple and reliable way to select a model with the optimal number of selected variables. This will greatly diminish the duration of the studies as well as the design stage, thereby reducing the cost of the project.

Of course, the choice of the range of variations is controversial because of its apparent subjectivity. However, our ability to predict the values of the fundamental physical constants by use of comparative uncertainty allows us to improve the scientific understanding of complex phenomena, and to apply this understanding to solve specific problems. In addition, the prospect of an additional solution to the problem will help researchers to understand the current situation and to identify specific ways to solve it.

\section{Conclusions}

In addition to the relative uncertainty analysis, the introduced approach could enable a new methodology that will help the additional monitoring accuracy of physical laws and fundamental physical constants. The use of the $\aleph$-hypothesis only limits the domain of applicability of measurement theory for uncertainties that are much larger than the uncertainty of the physical-mathematical model due to its finiteness.

By introducing the comparative uncertainty concept along with known physical laws, we can verify the required relative uncertainty values of fundamental physical constants that must be recommended for identifying concrete ways to perfect SI.

The suggested approach is a mathematical tool that allows one to describe a physical system with the lowest uncertainty, which is a surprisingly simple relation.

The $\aleph$-hypothesis might be applicable to experimental verification. In general, it is available when the researcher has all the information about the changes interval of the main variable. Moreover, the $\aleph$-hypothesis provides new functionalities useful for micro- and macro-physics, including engineering, astronomy, and quantum electrodynamics.

The comparative uncertainty is a peculiar metric for assessing the measurement accuracy of physical laws and fundamental physical constants.

\section{Acknowledgements}

The author extends his deep appreciation to several people. These include Prof. 
V. Lyandres for reading and commenting on some parts of this manuscript through various stages of its development. The author also wishes to thank Dr. V. B. Rzevskaya, late Prof. E. I. Guigo, late Prof. A. A. Guhman for their years of support during the development of the proposed approach.

\section{References}

[1] Henrion, M. and Fischhoff, B. (1986) Assessing Uncertainty in Physical Constants. American Journal of Physics, 54, 791-798. http://goo.gl/nfMcNW https://doi.org/10.1119/1.14447

[2] Menin, B.M. (2014) Comparative Uncertainty of the Phenomena Model. International Refereed Journal of Engineering and Science, 3, 68-76. http://goo.gl/DwgYXY

[3] Sonin, A.A. (2001) The Physical Basis of Dimensional Analysis. 2nd Edition, Department of Mechanical Engineering, MIT, Cambridge. http://goo.gl/2BaQM6

[4] NIST Special Publication 330 (SP330) (2008) The International System of Units (SI). National Institute of Standards and Technology, Gaithersburg. http://goo.gl/4mcVwX

[5] Jakulin, A. (2005) Symmetry and Information Theory. Symmetry: Culture and Science, 16, 7-26. http://goo.gl/QGBVoU

[6] Sedov, L.I. (1993) Similarity and Dimensional Methods in Mechanics, 10th Edition, CRC Press, London. https://goo.gl/S3GY0U

[7] Menin, B.M. (2016) Validation Metric for Gravitational Constant Measurement Based on Comparative Uncertainty. International Refereed Journal of Engineering and Science, 5, 36-42. http://irjes.com/Papers/vol5-issue12/E5123642.pdf

[8] Rosi, G., Sorrentino, F., Cacciapuoti, L., Prevedelli, M. and Tino, G.M. (2014) Precision Measurement of the Newtonian Gravitational Constant Using Cold Atoms. Nature, 510, 518-521. https://doi.org/10.1038/nature13433

[9] Quinn, T.J., Speake, C.C., Richman, S.J., Davis, R.S. and Picard, A.A. (2001) New Determination of $G$ Using Two Methods. Physical Review Letters, 87, Article ID: 111101.

[10] Gundlach, J.H. and Merkowitz, S.M. (2000) Measurement of Newton's Constant Using a Torsion Balance with Angular Acceleration Feedback. Physical Review Letters, 85, 2869-2872. https://doi.org/10.1103/PhysRevLett.85.2869

[11] Kleinvoß, U., Meyer, H., Piel, H. and Hartmann, S. (2002) Personal Communication.

[12] Schlamminger, St., Holzschuh, E. and Kündig, W. (2002) Determination of the Gravitational Constant with a Beam Balance. Physical Review Letters, 89, Article ID: 161102. https://doi.org/10.1103/PhysRevLett.89.161102

[13] Mohr, P.J. and Taylor, B.N. (2005) CODATA Recommended Values of the Fundamental Physical Constants: 2002. Reviews of Modern Physics, 77, 1-107. https://doi.org/10.1103/RevModPhys.77.1

[14] Armstrong, T.R. and Fitzgerald, M.P. (2003) New Measurements of G Using the Measurement Standards Laboratory Torsion Balance. Physical Review Letters, 91, Article ID: 201101. https://doi.org/10.1103/PhysRevLett.91.201101

[15] Schlamminger, S., Holzschuh, E., Kündig, W., Nolting, F., Pixley, R.E., Schurr, J. and Staumann, U. (2006) A Measurement of Newton's Gravitational Constant. Physical Review D, 74, Article ID: 082001. https://doi.org/10.1103/PhysRevD.74.082001

[16] Mohr, P.J., Taylor, B.N. and Newell, D.B. (2008) CODATA Recommended Values 
of the Fundamental Physical Constants: 2006. Reviews of Modern Physics, 80, 633730. https://goo.gl/ZqKxr https://doi.org/10.1103/RevModPhys.80.633

[17] Luo, J., Liu, Q., Tu, L.-C., Shao, C.-G., Liu, L.-X., Yang, S.-Q., Li, Q. and Zhang, Y.-T. (2009) Determination of the Newtonian Gravitational Constant G with Timeof-Swing Method. Physical Review Letters, 102, Article ID: 240801. https://10.1103/PhysRevLett.102.240801 https://doi.org/10.1103/PhysRevLett.102.240801

[18] Parks, H.V. and Faller, J.E. (2010) Simple Pendulum Determination of the Gravitational Constant. Physical Review Letters, 105, Article ID: 110801. https://doi.org/10.1103/PhysRevLett.105.110801

[19] Mohr, P.J., B.N. Taylor, B.N. and Newell, D.B. (2012) CODATA Recommended Values of the Fundamental Physical Constants: 2010. Reviews of Modern Physics, 84, 1527-1604. http://physics.nist.gov/cuu/Constants/codata.pdf

[20] Quinn, T.J., Speake, C.C., Parks, H.V. and Davis, R.S. (2014) The Newtonian Constant of Gravitation-A Constant Too Difficult to Measure? An Introduction. Philosophical Transactions of the Royal Society A, 372, Article ID: 20140253. http://goo.gl/1EpvMC https://doi.org/10.1098/rsta.2014.0253

[21] NIST (2014) CODATA Internationally Recommended 2014 Values of the Fundamental Physical Constants. https://goo.gl/IYcnBG

[22] Cadoret, M., Mirandes, E., Clade, P., Gurlatti-Khelifa, S., Schwob, C., Nez, F., Julien, L. and Biraben F. (2008) Combination of Bloch oscillations with a Ramsey-Borde Interferometer: New Determination of the Fine Structure. Physical Review Letters, 101, Article ID: 230801. https://arxiv.org/abs/0810.3152v1 https://doi.org/10.1103/PhysRevLett.101.230801

[23] Gabrielse, G., Hanneke, D., Kinoshita, T., Nio, M. and Odom, B. (2007) New Determination of the Fine Structure Constant from the Electron $g$ Value and QED. Physical Review Letters, 99, Article ID: 039902. https://goo.gl/fO23fx

[24] Hanneke, D., Fogwell, S. and Gabrielse, G. (2008) New Measurement of the Electron Magnetic Moment and the Fine Structure Constant. Physical Review Letters, 100, Article ID: 120801. http://arxiv.org/pdf/0801.1134.pdf https://doi.org/10.1103/physrevlett.100.120801

[25] Schonfeld, E. and Wilde, P. (2008) Electron and Fine Structure Constant II. Metrologia, 45, 342-355. http://goo.gl/gkAmmp https://doi.org/10.1088/0026-1394/45/3/012

[26] Bouchendira, R., Clade, P., Gurlatti-Khelifa, S., Nez F. and Biraben, F. (2011) New Determination of the Fine Structure Constant and Test of the Quantum Electrodynamics, Physical Review Letters, 106, Article ID: 080801.

https://arxiv.org/pdf/1012.3627.pdf https://doi.org/10.1103/PhysRevLett.106.080801

[27] Cadoret, M., Mirandes, E., Clade, P., Gurlatti-Khelifa, S., Schwob, C., Nez, F., Julien, L. and Biraben F. (2008) Combination of Bloch oscillations with a Ramsey-Borde Interferometer: New Determination of the Fine Structure Constant, Physical Review Letters, 101, Article ID: 230801. https://arxiv.org/abs/0810.3152v1

[28] Aoyama, T., Hayakawa, M., Kinoshita, T. and Nio, M. (2012) Tenth-Order QED Contribution to the Electron g-2 and an Improved Value of the Fine Structure Constant. Physical Review Letters, 109, Article ID: 111807. https://arxiv.org/pdf/1205.5368.pdf

[29] Bouchendira, R., Cladé, P., Guellati-Khélifa, S., Nez, F. and Biraben, F. (2013) State 
of the Art in the Determination of the Fine Structure Constant: Test of Quantum Electrodynamics and Determination of h/mu. Annalen der Physik, 525, 484-492. https://arxiv.org/pdf/1309.3393.pdf

[30] Mohr, P.J., Newell, D.B. and Taylor, B.N. (2015) CODATA Recommended Values of Fundamental Physical Constants: 2014. National Institute of Standards and Technology, Gaithersburg, 1-11. http://arxiv.org/pdf/1507.07956v1.pdf

[31] Kirakosyan, G.S. (2010) The Correlation of the Fine Structure Constant with the Redistribution of Intensities in Interference of the Circularly Polarized Compton's Wave. General Physics, 1-7. http://n-t.ru/tp/ng/fs1.pdf

[32] Steiner, R. (2013) History and Progress on Accurate Measurements of the Planck Constant. Reports on Progress in Physics, 76, Article ID: 016101.

http://goo.gl/s1GomR https://doi.org/10.1088/0034-4885/76/1/016101

[33] Stein J. (2011) Planck's Constant: The Number That Rules Technology, Reality, and Life. Quantum Physics/The Cosmos. http://www.pbs.org/wgbh/nova/blogs/physics/2011/10/plancks-constant/

[34] Steiner, R.L., Williams, E.R., Liu, R. and Newell, D.B. (2007) Uncertainty Improvements of the NIST Electronic Kilogram. IEEE Transactions on Instrumentation and Measurement, 56, 592-596. https://doi.org/10.1109/TIM.2007.890590

[35] Robinson, I.A., and Kibble, B.P. (2007) An Initial Measurement of Planck's Constant Using the NPL Mark II Watt Balance. Metrologia, 44, 427-440. https://doi.org/10.1088/0026-1394/44/6/001

[36] Eichenberger, A., Baumann, H., Jeanneret, B., Jeckelmann, B., Richard, P. and Beer, W. (2011) Determination of the Planck Constant with the METAS Watt Balance. Metrologia, 48, 133-141. https://doi.org/10.1088/0026-1394/48/3/007

[37] Andreas, B., et al. (2011) Determination of the Avogadro Constant by Counting the Atoms in a 28Si Crystal. Physical Review Letters, 106, Article ID: 030801. https://doi.org/10.1103/PhysRevLett.106.030801

[38] Schlamminger, S., Haddad, D., Seifert, F., Chao, L.S., Newell, D.B., Liu, R., Steiner, R.L. and Pratt, J.R. (2014) Determination of the Planck Constant Using a Watt Balance with a Superconducting Magnet System at the National Institute of Standards and Technology. Metrologia, 51, 1-22. http://goo.gl/hxLYTJ

[39] Sanchez, C.A., Wood, B.M., Green, R.G., Liard, J.O. and Inglis, D. (2014) A Determination of Planck's Constant Using the NRC Watt Balance. Metrologia, 51, 5-14. https://doi.org/10.1088/0026-1394/51/2/S5

[40] Gaiser, C. and Fellmuth B. (2012) Low-Temperature Determination of the Boltzmann Constant by Dielectric-Constant Gas Thermometry. Metrologia, 49, 4-7.

https://goo.gl/EmxfEG https://doi.org/10.1088/0026-1394/49/1/L02

[41] Gavioso, R.M., Benedetto, G., Giuliano Albo, P.A., Madonna Ripa, D., Merlone, A., Guianvarc'h, C., Moro, F. and Cuccaro, R. (2010) A Determination of the Boltzmann Constant from Speed of Sound Measurements in Helium at a Single Thermodynamic State. Metrologia, 47, 387-409. https://goo.gl/G2IAIv https://doi.org/10.1088/0026-1394/47/4/005

[42] Schmidt, J.W., Gavioso, R.M., May, E.F. and Moldover, M.R. (2007) Polarizability of Helium and Gas Metrology. Physical Review Letters, 98, Article ID: 254504. https://doi.org/10.1103/PhysRevLett.98.254504

[43] Pitre, L., Guianvarc'h, C., Sparasci, F., Guillou, A., Truong, D., Hermier, Y. and Himbert, M.E. (2009) An Improved Acoustic Method for the Determination of the Boltzmann Constant at LNE-INM/CNAM. Comptes Rendus Physique, 10, 835-848. 
https://doi.org/10.1016/j.crhy.2009.11.001

[44] Sutton, G., Underwood, R., Pitre, L., de Podesta, M. and Valkiers, S. (2010) Acoustic Resonator Experiments at the Triple Point of Water: First Results for the Boltzmann Constant and Remaining Challenges. International Journal of Thermophysics, 31, 1310-1346. https://10.1007/s10765-010-0722-z https://doi.org/10.1007/s10765-010-0722-Z

[45] Pitre, L., Sparasci, F., Truong, D., Guillou, A., Risegari, L. and Himbert, M.E. (2011) Measurement of the Boltzmann Constant kB Using a Quasi-Spherical Acoustic Resonator. International Journal of Thermophysics, 32, 1825-1886.

https://goo.gl/CBRo0w https://doi.org/10.1007/s10765-011-1023-x

[46] Benz, S.P., Pollarolo, A., Qu, J., Rogalla, H., Urano, C., Tew, W.L., Dresselhaus, P.D. and White, D.R. (2011) An Electronic Measurement of the Boltzmann Constant. Metrologia, 48, 142-153. https://doi.org/10.1088/0026-1394/48/3/008

[47] Fellmuth, B., Fischer, J., Gaiser, C., Jusko, O., Priruenrom, T., Sabuga, W. and Zandt, T. (2011) Determination of the Boltzmann Constant by Dielectric-Constant Gas Thermometry. Metrologia, 48, 382-390. https://goo.gl/CcS1lK https://doi.org/10.1088/0026-1394/48/5/020

[48] Mohr, P.J., Taylor B.N. and Newell, D.B. (2016) CODATA Recommended Values of the Fundamental Physical Constants: 2014. Reviews of Modern Physics, 88, Article ID: 035009. https://goo.gl/O0x4cv https://doi.org/10.1103/RevModPhys.88.035009

[49] Qu, J., Benz, S.P., Pollarolo, A., Rogalla, H., Tew, W.L., White R. and Zhou, K. (2015) Improved Electronic Measurement of the Boltzmann Constant by Johnson Noise Thermometry. Metrologia, 52, 242-256. https://goo.gl/0ilnYq https://doi.org/10.1088/0026-1394/52/5/S242

\section{Scientific Research Publishing}

Submit or recommend next manuscript to SCIRP and we will provide best service for you:

Accepting pre-submission inquiries through Email, Facebook, LinkedIn, Twitter, etc. A wide selection of journals (inclusive of 9 subjects, more than 200 journals)

Providing 24-hour high-quality service

User-friendly online submission system

Fair and swift peer-review system

Efficient typesetting and proofreading procedure

Display of the result of downloads and visits, as well as the number of cited articles

Maximum dissemination of your research work

Submit your manuscript at: http://papersubmission.scirp.org/

Or contact jamp@scirp.org 